\title{
Potential of electricity generation from renewable energy sources in standard domestic houses
}

\author{
R. D. Ionescu ${ }^{1,2}$, M. Ragazzi ${ }^{1}$, L. Battisti ${ }^{1}$, E. C. Rada ${ }^{1}$ \\ $\& \mathrm{G}$. Ionescu ${ }^{1,3}$ \\ ${ }^{I}$ Department of Civil, Environmental and Mechanical Engineering, \\ University of Trento, Italy \\ ${ }^{2}$ Department of Product Design, Mechatronics and Environment, \\ Transilvania University of Brasov, Romania \\ ${ }^{3}$ Department of Energy Production and Use, \\ Politehnica University of Bucharest, Romania
}

\begin{abstract}
In this paper the potential of several sustainable energy sources is examined referring to a standard domestic house with 4 inhabitants. The selected options were: wind energy, solar energy (photovoltaic), domestic waste and wastewater. The aim was to define how much of the energy demand for the proposed standard domestic house can be covered by wind energy or photovoltaic panels and how much we can obtain by an efficient waste and wastewater management. The feasibility of these solutions was also compared.

Keywords: domestic wastewater, photovoltaic, household waste, renewable energy, urban wind turbine, wind energy.
\end{abstract}

\section{Introduction}

During recent years, the increased interest towards renewable energy sources as an alternative to conventional ones has grown [1]. The new sustainability directives related to decreasing the impact of energy sources on the environment induced the researchers to more and more efficient and less hazardous ways of obtaining energy. 
The feasibility of implementing the photovoltaic-wind hybrid systems for the standard domestic house is under development at scientific level. Generally, a small power, vertical axis wind turbine is applied [2,3]. This is not the only option for exploiting a building in term of energy generation.

Worldwide the Municipal Solid Waste (MSW) management policymakers are mainly focused on environmental and economic strategies [4]. The European Union waste directive foreseen that by $2020,50 \%$ of the produced urban MSW must be valorised by recycling and recovering. The efficiency of MSW selective collection (SC) has an important role in the characteristics of Refused Municipal Solid Waste (RMSW), therefore also on their treatment technology [5-7] more and more oriented to energy valorisation. To this concern, typically the mass and energy balances refer to wide areas, but some considerations are interesting also at domestic scale.

In a region in the North of Italy, with around 500,000 inhabitants resident, about $215,052 \mathrm{t}_{\mathrm{MSW}} \mathrm{y}^{-1}$ were produced, from which one third was represented by RMSW [8]. Indeed, in the selected area the SC reaches up to $68 \%$, due the optimization of kerbside collection. In 20 years of waste management improvement, in the selected area the SC increase was remarkable [9]. Additionally, as extreme effect of the high SC, the RMSW can be considered a sort of solid recovered fuel (SRF), partially biomass-like, that can be exploited in a centralised incineration plant in order to produce electricity and heat [10].

The domestic wastewater in the same selected area represents an important inflow source. The domestic wastewater results from different household activities, influencing both the quantitative and qualitative flow. The aerobic technologies have been applied on domestic wastewater treatment using activated sludge processes due to the remarkable results on nutrient removal. Its treatment generates sewage sludge. The anaerobic digestion (AD) treatment of the produced sewage sludge is typical adopted for medium and large size plant $[11,12]$. From the point of view of energy valorisation this process is interesting for the generation of biogas with a significant content of methane.

AD can be adopted for the exploitation of food waste source separated too.

Summing up, in the present study the energy production from the following sources was analysed in order to assess the relative importance of them:

- Electricity from domestic wind turbine;

- Electricity from domestic photovoltaic panels;

- Electricity from biogas obtained from the sewage sludge AD;

- Electricity from biogas obtained from the food waste AD;

- Electricity and heat from a centralized valorisation of RMSW (only domestic contribution).

Heat from $\mathrm{AD}$ was not taken into account as used for operating the AD reactors at a steady temperature. 


\section{Material and methods}

\subsection{Renewable energy exploitation potential}

In the selected case - study a standard domestic house (SDH), with 4 inhabitants was considered. The location is pointed out in Figure 1. The input parameters were: useful surface area of $100 \mathrm{~m}^{2}$, building height $12 \mathrm{~m}, 4$ inhabitants (2 adults and 2 children). The SDH, presented in Figure 1, is equipped with a small power vertical axis wind turbine and photovoltaic panels. For the selected case-study, data regarding wind were used from a local weather station.
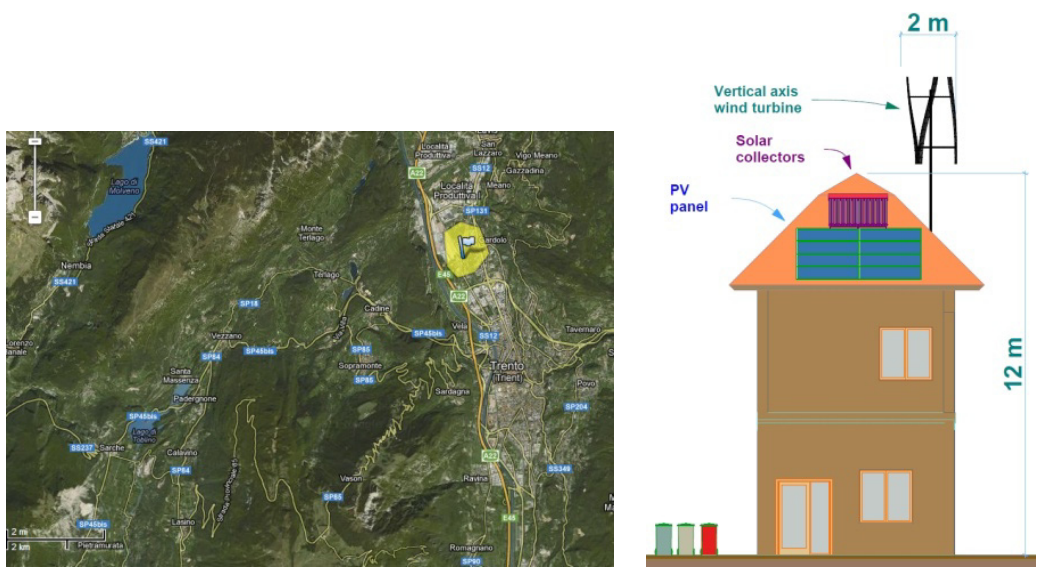

Figure 1: $\quad$ Location of SDH with the small wind turbine and solar panels.

The implementation of a wind turbine in the urban environment raises a series of specific design problems, compared to open field implementation, such as: the type of wind turbine, the emplacement, the wind resources, and the size of the wind turbine compared to the building. The Darrieus type vertical axis wind turbines was chosen, due to its better performance in urban turbulent wind [13], and placed on the rooftop of the building. The chosen turbine is able to cope with turbulent flows and can take wind from any direction.

The location of the wind turbine on the roof was chosen in order to take advantage from the elevation of the building. Figure 2 shows clearly the effect of

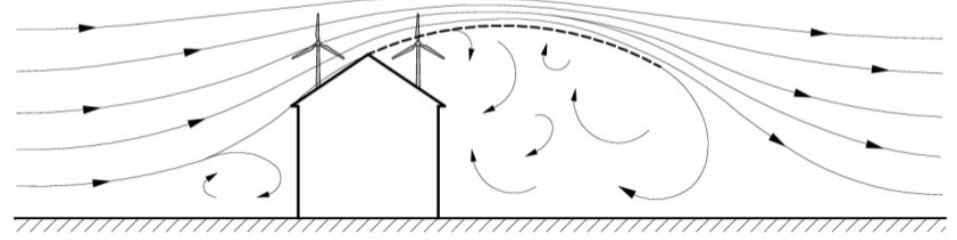

Figure 2: $\quad$ The effect of positioning a wind turbine on the roof. 
a too short supporting tower on the downstream erected turbine, which let the latter to operate within the separation bubble induced from the roof. In this condition, the turbine will work in an irregular mode, with a severe reduction of the energy produced and a sensible reduction of its life [14].

Previous studies have shown that there is a critical ratio between the rotor dimensions and the building dimensions, and thus, for a certain building height you are restricted to a corresponding turbine size. For this purpose the following algorithm is used [15], which considers the temporal scale of the turbulent structure for the building and the time constant for the turbine, in order to obtain a stationary wake. For avoiding unsteady effects the following relationship must be complied with:

where

$$
\tau_{\text {rot }}<\tau_{\text {turb }}, \quad \tau_{\text {turb }}=\frac{\bar{H}}{V_{0}} \quad \text { and } \quad \tau_{\text {rot }}=\frac{k_{D}}{V_{0}}
$$

$\bar{H}=$ medium height of the buildings

$V_{0}=$ wind speed

$k_{D}=$ length of the turbine wake, with $k=3-6$.

Taking into account the literature and the meteorological data (wind velocity of $6.5 \mathrm{~m} \mathrm{~s}^{-1}$ ), for the selected SDH, the maximum diameter for the turbine should be no more than $2 \mathrm{~m}$. The generated energy will be calculated taking into account the following formula:

where

$$
E=R_{c} * C_{f} * 8,760
$$

$\mathrm{E}=$ energy generated by wind turbine

$R_{c}=$ rated capacity of the wind turbine

$C_{f}=$ capacity factor of the wind turbine class (the ratio of the actual output of the wind turbine to its potential output).

The capacity factor for wind turbines smaller than $1.5 \mathrm{~kW}$, following the British Wind Energy Association (BWEA) standard is 0.1 [16]. The maximum annual energy production (AEP) for the chosen wind turbine can be calculated taking into account the following formula:

$$
A E P=P_{\text {max }} * 8,760 * 0.1\left[\mathrm{kWh} \mathrm{y}^{-1}\right]
$$

For the photovoltaic panels, a $1 \mathrm{kWp}$ installed peak solution was chosen, of crystalline silicone panels (estimated system loss $14 \%$ and slope $45^{\circ}$ ), which completes the wind-solar hybrid system. For estimating the AEP for the selected area it was used as a reference guide the values obtained by PVGIS-CMSAF [17].

\subsection{Domestic waste exploitation potential}

The energy potential from household waste (HW), food waste and sewage sludge from wastewater generation for the chosen case study is presented below. 
In the case-study area in the North of Italy, RMSW averagely generated by a citizen was estimated to be $111.3 \mathrm{~kg}_{\mathrm{HW}} \mathrm{inh}^{-1} \mathrm{y}^{-1}$ [8]. The residual household waste (RHW) resulted from the improper SC was estimated about $79.16 \mathrm{~kg}_{\mathrm{RHW}}$ inh $^{-1} \mathrm{y}^{-1}$. Its composition in the selected case-study is presented in Figure 3. Table 1 presents the energetic potential, moisture and non-volatile solids (NVS=inert) content for each waste fraction of considered waste. These data allow assessing the LHV of the RHW, which can be valorised in a centralised incinerator with energy recovery.

Table 1: $\quad$ Proximate and energetic characteristics of waste fractions.

\begin{tabular}{|l|c|c|c|}
\hline Waste fraction & Moisture [\%] & NVS [\%] & LHV [kcal $\left.\mathbf{~ k g}^{-\mathbf{1}}\right]$ \\
\hline Food waste & 63.9 & 9.0 & 951 \\
\hline Green waste & 65.0 & 1.6 & 1,065 \\
\hline Paper and cardboard & 23.0 & 44.5 & 2,784 \\
\hline Plastics & 4.5 & 8.2 & 7,527 \\
\hline Glass & 2.0 & 96.9 & 0 \\
\hline Metals & 3.0 & 92.6 & 0 \\
\hline Wood & 21.9 & 1.4 & 3,500 \\
\hline Textiles & 20.0 & 2.7 & 3,489 \\
\hline Composite & 4.5 & 31.0 & 4,500 \\
\hline Rubber & 2.2 & 8.1 & 7,000 \\
\hline Other & 49.0 & 5.8 & 600 \\
\hline Inert & 0.0 & 73.0 & 0 \\
\hline Diapers & 22.8 & 20.0 & 4,000 \\
\hline
\end{tabular}

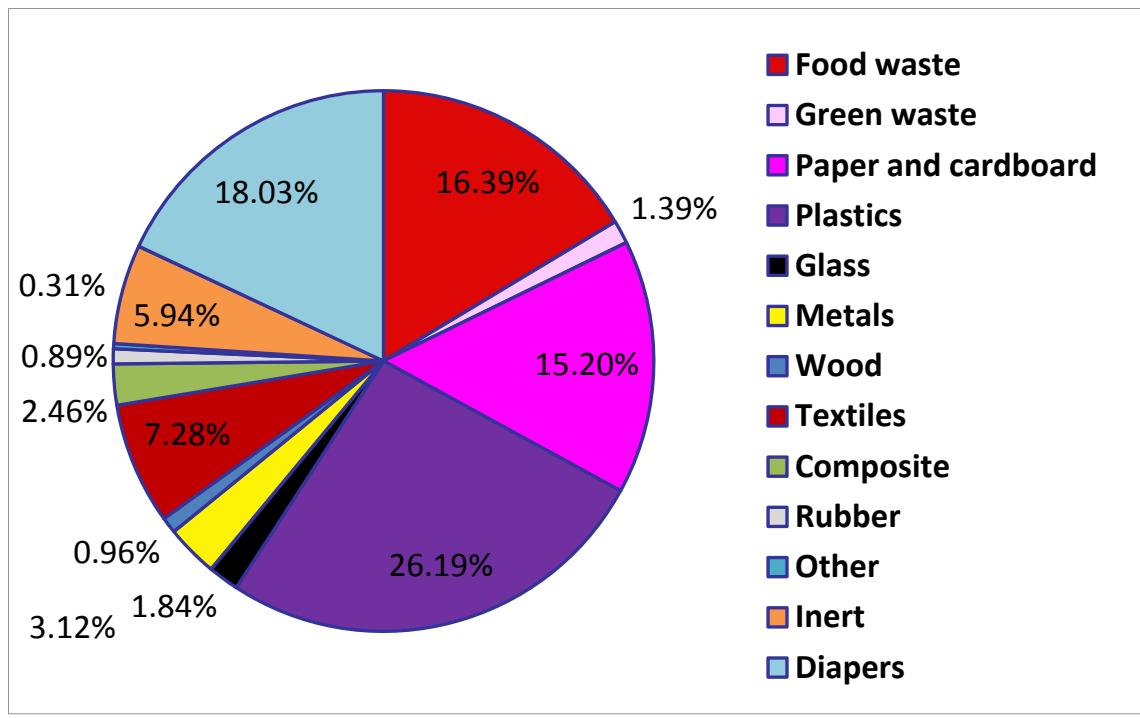

Figure 3: Household waste composition in the selected case-study. 
The food waste collected separately is supposed to be treated in an AD plant for biogas production. AD is an effective method that converts organic matter into renewable energy, with an electrical conversion efficiency of about $40 \%$ [18]. From the AD treatment, biogas is produced: $50-60 \%$ is methane, $40-50 \%$ is carbon dioxide, $1-3 \%$ is nitrogen and the same range can be found for hydrogen. The average calorific value of biogas is generally $21-23.5 \mathrm{MJ} \mathrm{m}^{-3}$. In this casestudy a specific generation of $60 \mathrm{~m}_{\mathrm{CH} 4}^{3}$ ton $^{-1}$ food waste and a yearly per capita collection of $100 \mathrm{~kg}$ of food waste were considered (2/3 of them of domestic origin).

SC has not only food waste as energetically valorisable stream; indeed some MSW fractions source separated need specific treatments for mass recovery that generate side streams of discarded materials with an interesting LHV. To this concern, in the calculations the discarded packaging waste with high energetic content resulting from the recycling process was considered commingled with the RHW. The resulted material can be associated with a sort of Solid Recovered Fuel and can be sent to an incineration plant for energy recovery. Generally the net efficiencies of the waste incineration plants can be assumed as $20 \%$ for electric and $64 \%$ for thermal conversion [7].

In the selected case-study it was assumed that one inhabitant produces about $3001_{\text {waste water }} \mathrm{inh}^{-1} \mathrm{~d}^{-1}$, with a $\mathrm{BOD}_{5}$ load as $60 \mathrm{~g} \mathrm{inh}^{-1} \mathrm{~d}^{-1}$. The resulting wastewater is treated mechanically and biologically, with settling stages that have a consequent generation of sewage sludge. Thanks to the AD applied to sewage sludge, the system can give about $20 \mathrm{l}_{\mathrm{CH} 4} \mathrm{inh}^{-1} \mathrm{~d}^{-1}$. This methane is the main compound of the biogas generated.

\section{Results and discussion}

In the selected SDH the average power output from the wind turbine will be around $0.4-1 \mathrm{~kW}$, and, as a result, the energy output can be computed with literature data [19]. Thus, the maximum annual energy production (AEP) for our wind turbine was assessed about $867 \mathrm{kWh}_{\mathrm{el}} \mathrm{y}^{-1}$.

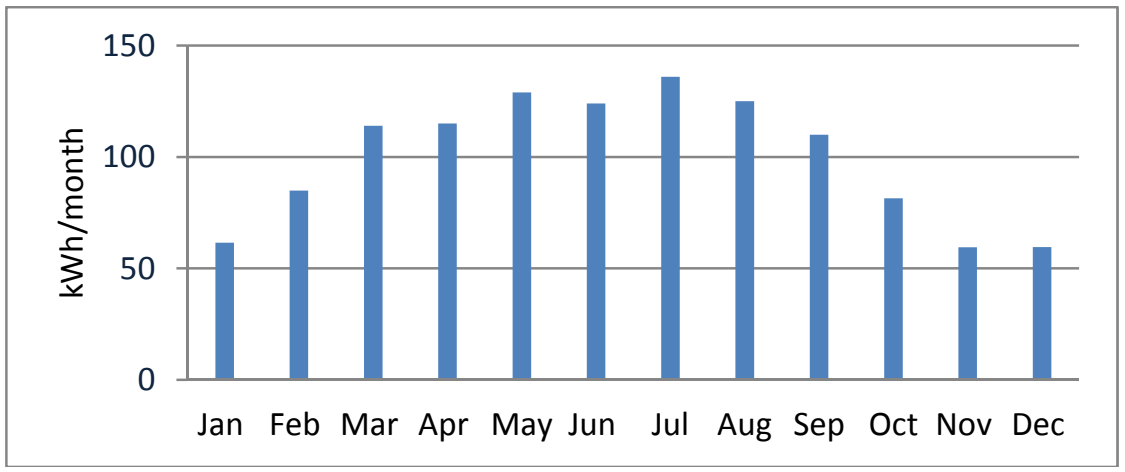

Figure 4: Monthly energy output from SDH integrated, fixed-angle PV system. 
From the photovoltaic panels, the monthly values obtained for the selected case-study are presented in Figure 4. The AEP resulted about $1200 \mathrm{kWh}_{\mathrm{el}} \mathrm{y}^{-1}$.

The domestic waste from a SDH with 4 inhabitants offers some sustainable results from the energy recovery point of view. In the case of food waste the adoption of anaerobic digestion in a centralized plant reveals an electric production of $64 \mathrm{kWh}_{\mathrm{el}}$ family ${ }^{-1} \mathrm{y}^{-1}$. From the environmental point of view the $\mathrm{CO}_{2}$ produced by biological activity such as biogas is considered innocuous because of its short life cycle in comparison with $\mathrm{CO}_{2}$ from fossil fuel use is of great concern because there is no way it is retuned and absorbed on earth. Similarly AD of sewage sludge gives $117 \mathrm{kWh}_{\mathrm{el}}$ family $^{-1} \mathrm{y}^{-1}$.

In the present case study the obtained SRF from the RHW has a lower heating value of $15,693 \mathrm{~kJ} \mathrm{~kg}^{-1}$. Taking into account the latest indication for SRF the final SRF class indicated by the new regulation is LHV class 3, chlorine class 2 and mercury class 1 [20].

The valorisation of the SRF flow produced by the standard house in a combustion co-generation plant could generate a thermal energy output of 883 $\mathrm{kWh}_{\mathrm{th}} \mathrm{y}^{-1}$ and electrical energy output of $276 \mathrm{kWh}_{\mathrm{el}} \mathrm{y}^{-1}$.

The Authority for the electrical energy and gas (AEEG) assessed that an Italian family needs in the average $2700 \mathrm{kWh} / \mathrm{y}$ [21].

Summing up, wind turbine can cover $32 \%$ of this need, PV $44 \%$, ADs $7 \%$, SRF $10 \%$. It is clear that a full coverage of the domestic demand of electricity needs an optimization of the domestic consumption (substitution of old apparatuses, latest generation lamps, etc.), but this target seems reachable.

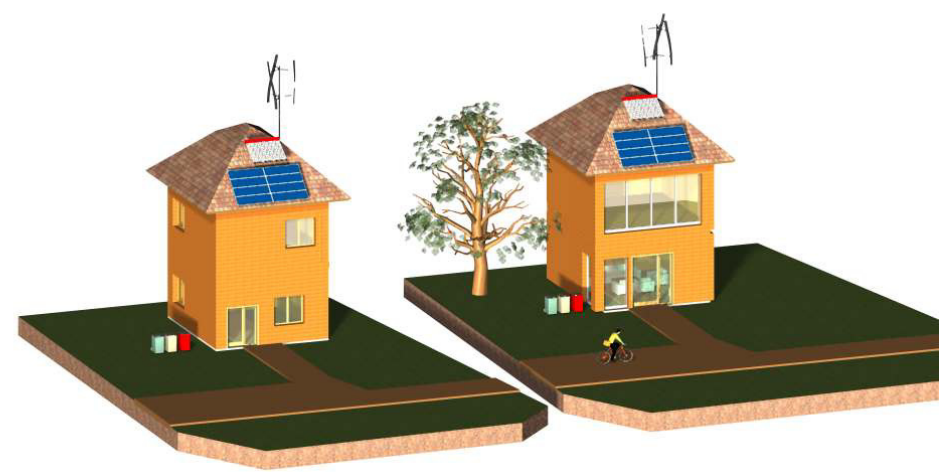

Figure 5: $\quad \mathrm{SDH}$ : an un-insulated house (left) and a passive house (right).

Considering an un-insulated house $\mathrm{SDH}$ and a passive $\mathrm{SDH}$ (Figure 5) different results for the amount of energy demand covered by the district heating from the RHW and discarded packaging can be calculated.

Previous studies [22] showed that the heat demand for non-insulated standard house can be higher than $180 \mathrm{kWh}_{\mathrm{th}} \mathrm{m}^{-2} \mathrm{y}^{-1}$, by contrast to a passive house where it need less than $30 \mathrm{kWh}_{\mathrm{th}} \mathrm{m}^{-2} \mathrm{y}^{-1}$. This last value is obtained by thermal solar panels and multiple solutions. Assuming the best performance, a surface of 100 $\mathrm{m}^{2}$ needs $3,000 \mathrm{kWh}_{\mathrm{th}} \mathrm{y}^{-1}$. As a consequence the district heating can cover about $29 \%$ of the request. 


\section{Conclusions}

Regarding the wind turbines, the study demonstrated that, when it comes to sustainable solutions, besides the efficiency, the payback time or the easiness of integration into the urban environment, an important factor is the implementation site. Consequently, every new case requires one to perform an analysis which takes into account the actual energy demand, the site potential for a certain renewable energy source. For instance, it can be concluded that it is recommended to consider from the beginning an integrated design project of building and wind turbine structure. However, we must not overlook the problems raised by building integration of the wind turbines, such as noise, vibrations, risk of structural collapse, low production of electricity, as well as the uncertainty of energy harvest for new integrated projects. For example in a wind turbine case the production can vary from 50 to $1000 \mathrm{kWh} \mathrm{y}^{-1}$ depending only on the type or the resources. Also, in the current market the turbines with less than $1 \mathrm{~kW}$ are still more expensive than the photovoltaic panel alternative. As the analysis has shown, the results are promising and support the further research initiative and improvement in renewable energy sources implementable in urban environment.

From an overall point of view, wind and photovoltaic panels can generate an amount of electricity more than 5 times higher than the amount obtainable from waste and wastewater (in centralized plants). This contribution is not negligible because the main target of their treatment is the solution of an environmental problem.

\section{References}

[1] Böhringer, C., Keller, A., van der Werf, E. Are green hopes too rosy? Employment and welfare impacts of renewable energy promotion, Energy Economics 36, pp. 277-285, 2013.

[2] Trivellato, F., Battisti, L., Miori, G. The ideal power curve of small wind turbines from field data, Journal of Wind Engineering and Industrial Aerodynamics 107-108, pp. 263-273, 2012 .

[3] Shadmand, M. B. and Balog, R.S. Optimization of photovoltaic-wind hybrid system for apartment complexes and other community living environments by minimizing excess capacity, Proceedings of Record of the IEEE Photovoltaic Specialists Conference, pp. 531-536, 2012.

[4] Ragazzi, M. and Rada, E. C. Multi-step approach for comparing the local air pollution contributions of conventional and innovative MSW thermochemical treatments, Chemosphere 89(6), pp. 694-701, 2012.

[5] Consonni, S., Giugliano, M., Massarutto, A., Ragazzi, M., Saccani, C. Material and energy recovery in integrated waste management systems: Project overview and main results, Waste Management 31(9-10), pp. 2057 206, 2011. 
[6] Ragazzi, M. and Rada, E. C. Effects of recent strategies of selective collection on the design of municipal solid waste treatment plants in Italy, WIT Transactions on Ecology and the Environment 109, pp. 613-620, 2008.

[7] Ionescu, G. and Rada, E.C. Material and energy recovery in a Municipal Solid Waste System: Practical Applicability, International Journal Of Environment And Resource 1(1) p. 26-30, 2012.

[8] PAT - Autonomous Province of Trento, 2012. Available at: www.rifiuti.provincia.tn.it. Accessed 2013.

[9] Rada, E.C., Ragazzi, M., Merler, G., Ionescu, G., Comparative analysis between two case studies based on the same integrated system for MSW management, Proceedings of $4^{\text {th }}$ International Conference on Engineering for Waste and Biomass Valorisation, 2012.

[10] Ragazzi M. and Rada E.C. RDF/SRF evolution and MSW bio-drying, WIT Transactions on Ecology and the Environment 163, pp. 199-208, 2012.

[11] Ragazzi M., Production, treatment and disposal of sludge in Italy, European Water Pollution Control 7(2), pp. 42-46, 1997.

[12] Kassab, G., Halalsheha, M., Klapwijkb, A., Fayyada, M., van Lierc, J.B., Sequential anaerobic-aerobic treatment for domestic wastewater - A review, Bioresource Technology 101(10), pp. 3299-3310, 2010.

[13] Battisti L., 2012, KyotoClub Gocce di sostenibilità Kyototube http://www.kyotoclub.org/index.php?go=30a2865, Accessed in February 2013.

[14] Mertens, S., Wind Energy in the built environment, Multi-Science, Essex, U.K., 2006.

[15] Battisti L., 2012, Scelta e installazione delle mini turbine eoliche, published on www.qualenergia.it, http://www.qualenergia.it/speciali/20120225-sceltae-installazione-delle-miniturbine-eoliche.

[16] Willcock, T., Appleby, S., UK Small-Scale Wind Survey. Installed capacity, Annual Generation and Market Growth. Report to Department of Energy and Climate Change, 2009.

[17] Photovoltaic Geographical Information System - Interactive Maps, http://re.jrc.ec.europa.eu/pvgis/apps4/pvest.php, Accessed in February 2013

[18] Cho, S.K., Im, W.T., Kim, D.H., Kim, M.H., Shin, H.S., Oh, S.E. Dry anaerobic digestion of food waste under mesophilic conditions: Performance and methanogenic community analysis, Bioresource Technology 131, pp. 210-217, 2013.

[19] Battisti, L., Wind Turbine Power Plants (Gli Impianti Motori Eolici), Ed. Lorenzo Battisti Ed. 2012.

[20] Rada E.C., Andreottoala G., RDF/SRF which perspective for its future in EU, Waste Management, 32(6), pp. 1059-1060, 2012.

[21] AEEG - Authority for Electricity and Gas, http://www.autorita.energia.it/, Accessed in February 2013.

[22] APE - Provincial Agency for Energy of Autonomous Province of Trento, www.energia.provincia.tn.it/certificazione_edifici, Accessed in February 2013. 